\title{
To thine own synapses be true?
}

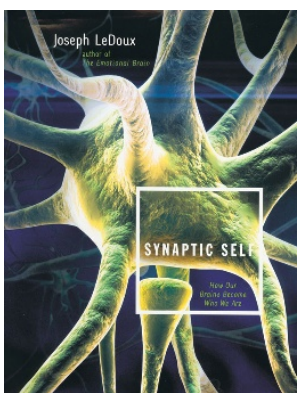

\author{
Synaptic Self: How Our Brains Become \\ Who We Are
}

by Joseph LeDoux

Viking Penguin, 2002. $\$ 29.95$

hardcover, pp 406

ISBN 0-670-03028-7

Reviewed by Jeffrey A. Gray

Synaptic Self is a beautifully written book, plentifully equipped with simple illustrative diagrams that build cumulatively from easy beginnings to almostas-easy endings. To get the message, though, you actually don't need to go beyond Figure 1.2. This has a central box labelled "synapses," with two arrows coming in from "nature" and "nurture," and one going out to "mind and behavior (the self)". I used to show a diagram much like this back in the 1960s, except that in place of "synapses" I had "brain". The point, then as now, was to show that all influences on adult personality, whether from genes or early environment, from chemicals or culture, must work by modifying the brain. It is surely easier to convince people of this now than it was then, given the far wider understanding of what the brain is and does. This increased understanding itself owes much to the sterling efforts of writers like LeDoux, who put complex neuroscientific discoveries and concepts into simple, comprehensible terms. Synaptic Self does this thoroughly and splendidly, offering the reader a RollsRoyce of a trip over what are otherwise some pretty rough roads-those of Hebbian learning, the different kinds of memory, fear conditioning, sensitization and so on, leading to places in the brain like the amygdala (LeDoux's influential amygdalocentricity takes its expected bow), the hippocampus and the frontal cortex. Much of behavioral neuroscience is here, and the naive reader will learn a lot.

A very good book indeed, then-but a pity about the title. For that same

Jeffrey A. Gray is Emeritus Professor of

Psychology at the Institute of Psychiatry, King's

College, London, De Crespigny Park, Denmark

Hill, London SE5 8AF, UK.

e-mail: j.gray@iop.kcl.ac.uk naive reader may, by the end, have learned much about the brain and how it controls learning and behavior, but rather little about 'the self' —at least, as one is initially likely to understand this term. It is, of course, a notoriously slippery term. LeDoux's own definition is "the totality of what an organism is physically, biologically, psychologically, socially and culturally" (p. 31). Well, yes; that covers pretty well everything. But the lay reader is likely to look for accounts of either (to use Tom Nagel's famous way of putting it) 'the feeling of what it is like to be me', or the way in which one person differs from every other. Alas, except in the broadest of terms, Synaptic Self doesn't really offer an account of either of these interpretations of 'the self'.

The conscious appreciation of the self is explicitly rejected as the book's topic by p. 10. This decision is backed up by appeal, among other things, to the fact that by far the greatest part of what the brain does happens without conscious awareness. This assertion is beyond question-indeed, it now stands as one of the best-supported empirical generalizations in behavioral neuroscience. Nonetheless, given the centrality of the conscious experience of self to the expectations encouraged by the book's title, this topic deserved more careful attention. Indeed, and not surprisingly, LeDoux finds it hard to keep to his self-imposed ban on consciousness. The subject turns up all over the place. To take just one example (p. 196), he writes: "These domain-specific kinds of short-term memory processes may underlie primitive conscious representations in animals that lack elaborate working memory functions." How, might one ask, does material like this get into a book that explicitly refuses to deal with the special problems posed by con- sciousness? The answer is, in the usual way: by sleight of hand relying upon the shared intuitions of author and reader. But that is not the empirical science that the book, quite correctly, sets up as its gold standard. Intuitions can be wrong. LeDoux would have been better advised either to stick to his guns and abjure discussions of consciousness altogether, or to deal with the topic fully and head-on.

LeDoux similarly leaves out of account just that body of research-the study of individual differences using multivariate statistical techniques like factor analysis-with the most to offer in addressing the question: What makes me different from everyone else? His justification of this rejection (Chapter 2) does not carry conviction, giving as it does great weight to the ideas of Freud and the psychoanalysts (why, I wonder, do hard-headed American neuroscientists continue to take seriously these rambling notions lacking all empirical basis?) and relying upon experiments of Walter Mischel (on the so-called Situation $\times$ Personality interaction), which have failed the test of time and replication. As it happens, in just the last few months there have been several reports of substantial correlations between factor-analytically derived personality traits such as extraversion and neuroticism (or polygenes themselves associated with these traits) and task-related brain activation detected with functional magnetic resonance imaging. One would have expected Synaptic Self to prepare the ground for such observations (especially as some center upon LeDoux's favorite organ, the amygdala) rather than to damn the whole enterprise.

The book closes with a resounding declaration of its main assertion: "You are your synapses. They are who you are." Well, yes; if we have to replace 'brain' with a more specific substrate of self (but why should we?), synapses have got as good a claim as anything else. But do they have a better claim? Why not seek a specific substrate of self within the cell? Gene expression, for example, is involved in both 'nature' and the growth of synapses, upon which LeDoux concentrates as the chief medium of expression of 'nurture'. And why, for that matter, not seek the substrate at a higher, systems level? One looks in vain in Synaptic Self for a serious discussion of issues such as these. So ignore the title, but have a good trip anyway. 